\title{
Eco-Cultural Tourism: A Tool for Environmental, Cultural and Economic Sustainability (A Case Study of Darap Village, West Sikkim)
}

\author{
Laitpharlang Cajee ${ }^{1}$ \\ ${ }^{1}$ Department of Geography, North Eastern Hill University, Shillong, India
}

\begin{abstract}
Eco-cultural tourism is a concept where both ecological and cultural aspects of a landscape are combined together creating a tourist paradise. It is travel to destinations where both cultural and natural endowments are the prime attractions and thereby considered to be a potential strategy to support conservation of natural habitats along with economic sustainability particularly to indigenous communities. North Eastern Region of India is one of the most mesmerizing regions of the Indian subcontinent that mirrors a perfect blending of life, culture and ecology. It is a relatively unexplored and unique area in terms of both ecology and cultural diversity and is characterized by the abundance of natural endowments; pristine forests with a huge diversity of flora and fauna, enchanting hills, fast flowing streams and meandering rivers, cascading waterfalls, snowcapped mountain ranges etc. Approximately there are 65 indigenous tribes in the region along with a host of sub-tribes having their own distinctive cultures, customs and traditions preserved till today. This article tries to argue through a case study of village tourism at Darap in West Sikkim that eco-cultural tourism is a potent force for the overall economic, social and cultural development as well biodiversity conservation in the region.
\end{abstract}

\section{Introduction}

Tourism related to both ecological and cultural attributes is becoming increasingly prevalent around the world [1-2] though travel to tourism sites of natural and cultural significance have existed at least since the time of Greek Antiquity, as reflected by Hellenistic world's invention of the Seven Wonders of the World. In more recent times, 157 countries have ratified the World Heritage Convention of 1972 (protecting the world's cultural and natural heritage) and 582 sites are inscribed on the UNESCO world heritage list.

One of the first definitions of ecotourism is stated as "environmentally responsible travel to relatively undisturbed natural areas in order to enjoy and appreciate nature that promotes conservation, which has low negative visitor impact and provided for beneficially active socio-economic involvement of local populations" [3]. The desire to spend leisure time in 'natural' settings is the key factor behind the recent and rapid growth of ecotourism. Ecotourism is a form of tourism inspired primarily by the natural history of an area, including its indigenous cultures and where a common theme in most definitions of ecotourism is responsible tourism in natural areas able to facilitate conservation objectives and able to promote environmentally sustainable development and 
conservation [4]. In 1991, The International Ecotourism Society (TIES) developed the definition of ecotourism as 'responsible travel to natural areas that conserves the environment and sustains the well-being of local people' with its aims such as ecological and socio-cultural integrity, responsibility and sustainability [5]. Ecotourism is a tool which ensures ecological, environmental, economical and cultural friendly tourism where tourism activities are being controlled by local communities of any respective area. In the recent past, nature tourism and ecotourism have emerged as principal options pursued by many countries both developed and developing, for integrating national parks, reserves, economic growth and rural development on a sustainable basis [6-8].

The concept of eco-cultural tourism which is therefore a subset of ecotourism is framed by integrating ecotourism as a sustainable form of natural resource-based tourism [9] and its prevalent culture. This is a new form of tourist activity where both the ecological and cultural aspects of a landscape are combined to create a site for tourists. It can also be explained as a travel to destinations where both the natural and cultural endowments are the prime attractions and considered to be a potential strategy to support conservation of natural habitats, exhibition of indigenous cultures and an alternative to economic sustainability. It is therefore a tool for economic empowerment and development of indigenous communities that keeps traditions alive and supports the protection of both natural and cultural heritage thereby increasing visitors' appreciation. In other words, it is a form of sustainable tourism, that is; "tourism which leads to management of all resources in such a way that economic, social and aesthetic needs can be fulfilled while maintaining cultural integrity, essential ecological processes, biological diversity and life support systems" [10]. This recent offshoot of tourism sector has grown to be a potential business in its own space as it showcases the natural beauty of the area, endemic flora and fauna, wildlife, local culture, traditional cuisines, dress and ornaments, art and heritage thereby strengthening the local communities socially and economically.

Northeast India being the most mesmerizing part of the Indian sub-continent mirrors perfect blending of life, culture and ecology. This region is relatively an unexplored and unique area in terms of both geography and cultural diversity and is characterized by the abundance of natural endowments such as dense and thick forests, variety of flora and fauna, meandering rivers, enchanting hills, waterfalls, snow-capped mountains etc. This region is the homeland of approximately 65 indigenous tribes along with a host of more than 200 sub-tribes having their own distinctive culture, customs and traditions that are preserved till today. This paper through a case study of Darap village, tries to argue that eco-cultural tourism is a potent force for sustainability in terms of economic, social and cultural development as well biodiversity conservation in the region. The study is a qualitative exploratory research based on both primary and secondary data. Primary data and information have been collected through field experiences. Secondary data have been collected from various relevant books, journals, websites, tourist brochures etc.

\section{National Wildlife Parks}

National parks around the world with rich wildlife assets are the topmost tourist attractions of the world. These national parks help to earn large revenue through tourism development. In addition most of these national parks are surrounded by rural areas which are seldom benefitted from the revenue earned from the development of tourism in the national parks. The rural areas remain to be underdeveloped in aspects of infrastructure and socio-economic status. Due to poverty, people of these areas are much prone to immoral or illegal activities like hunting, cutting of trees, poaching etc. which are threats to sustainability. Constrained by remoteness and underdevelopment, northeast India has limited options for economic development as traditional ways of earning a livelihood on crops or livestock provides only basic subsistence livelihood. With comparatively advantageous effects in income and employment generation, eco-cultural tourism is an option for enhancing rural lifestyles and for inducing positive changes in the distribution of income in underprivileged areas. Therefore, in a region like northeast India endowed with rich and colorful culture and tradition and where more than half of the population lives in rural areas eco-cultural tourism has a lot of potential for socio-economic development. 
Table 1. National Parks and Wildlife Sanctuaries of Northeast India

\begin{tabular}{|l|c|c|c|}
\hline \multicolumn{1}{|c|}{ States } & National Parks & Wildlife Sanctuaries & Total Protected Areas \\
\hline Assam & 5 & 18 & 23 \\
\hline Arunachal Pradesh & 2 & 11 & 13 \\
\hline Manipur & 1 & 1 & 2 \\
\hline Meghalaya & 2 & 3 & 5 \\
\hline Mizoram & 2 & 8 & 10 \\
\hline Nagaland & 1 & 3 & 4 \\
\hline Sikkim & 1 & 6 & 6 \\
\hline Tripura & 2 & $\mathbf{5 4}$ & $\mathbf{7 0}$ \\
\hline Grand Total & $\mathbf{1 6}$ & & \\
\hline
\end{tabular}

Source: www.fsi.org.in (April 2011)

Eco-cultural tourism activities in and around national parks and wildlife sanctuaries include expeditions for wildlife and flora including bird watching as these are areas rich in biodiversity and least disturbed by anthropogenic activities. Such areas are also famous for trekking both long and short distances and for nature walks to the delight of tourists. National parks and wildlife sanctuaries also provides one of the best fishing and angling spots and such other forms of adventure tourism such as river rafting, etc. combined along with varied cultural experiences through homestays. Homestays has been the most widely preferred lodging arrangement for an eco-cultural tourist. Overnight stays that can be extended to 5 - 7 days in traditional home made cottages with traditional lifestyle and cuisines are of high demand. Other cultural aspects experienced during such homestays are the exposure to various traditional skills such as indigenous fishing techniques, farming systems, weaving and cane work, traditional dances and merrymaking, costumes that includes different types of dress and ornaments, jewelry and such others.

\section{Darap Eco-Cultural Tourism}

Darap a village, located in the west district of Sikkim is approximately six kilometers away from tourist destination, Pelling and located at the fringe of the Kanchenjunga National Park. The village of Darap clings to the foothills of the Sikkim Himalaya in the shadow of Kanchenjunga situated at an altitude 1600 meters from mean sea level. Darap village had earlier faced a lot of challenges with livelihood where poverty was prevalent and people were engaged in cattle herding, poultry and resource extraction from forests such as edible herbs, timber felling for construction, charcoal and fuel wood. Shifting cultivation was also largely prevalent and subsistence. 


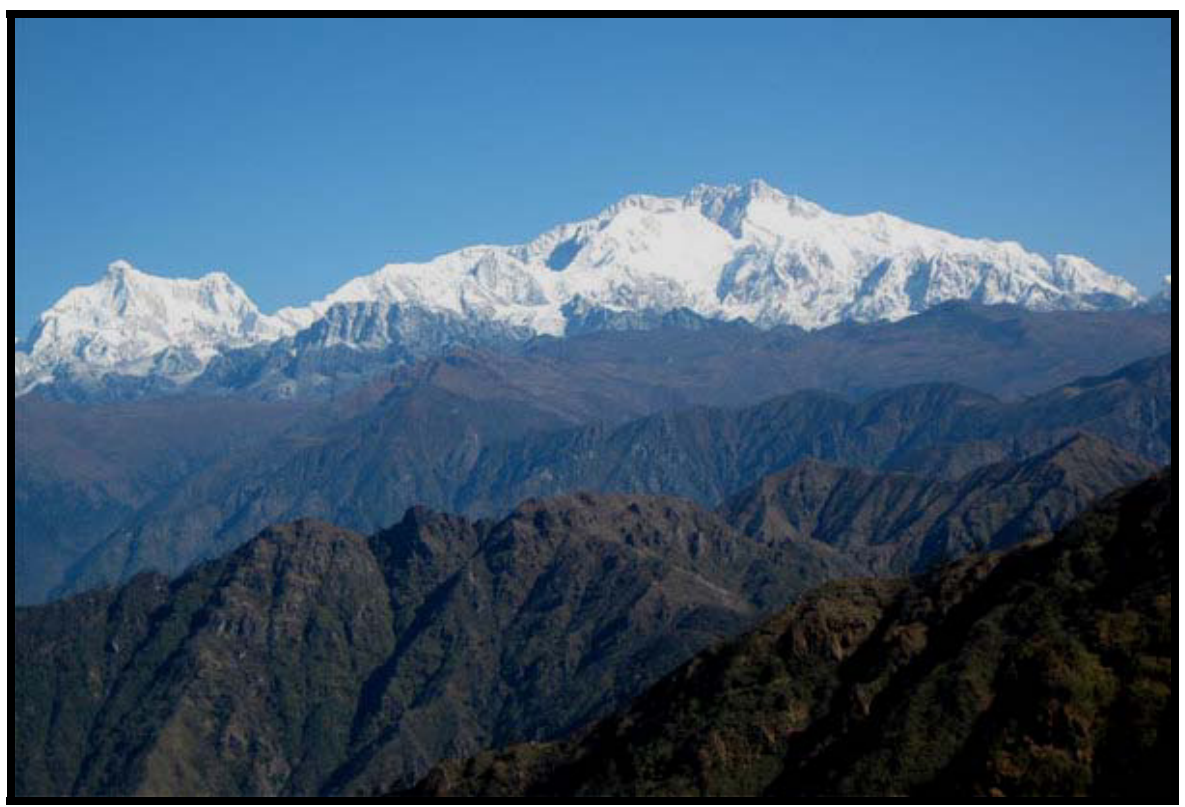

Figure 1. View of Kachenjunga from Darap village

With the evolution of village tourism in the form of eco-cultural tourism in Darap in 2005 scenic spots, historical sites, lakes, cultural activities are getting due attention at the hands of local people of the region. This changed the local economy of the village and is flourishing in multiple ways. Home stays started increasing in due course of time and even some residential buildings are being converted for tourism purposes. Tourism development in the village started with 8 families and is first introduced to about 30 ethnic houses as home stays, each family having two-three single or double bed rooms to accommodate the tourists. With these 30 home stays in the village available to tourists, the village has progressed with a huge potential of attracting tourists from different parts of the world.

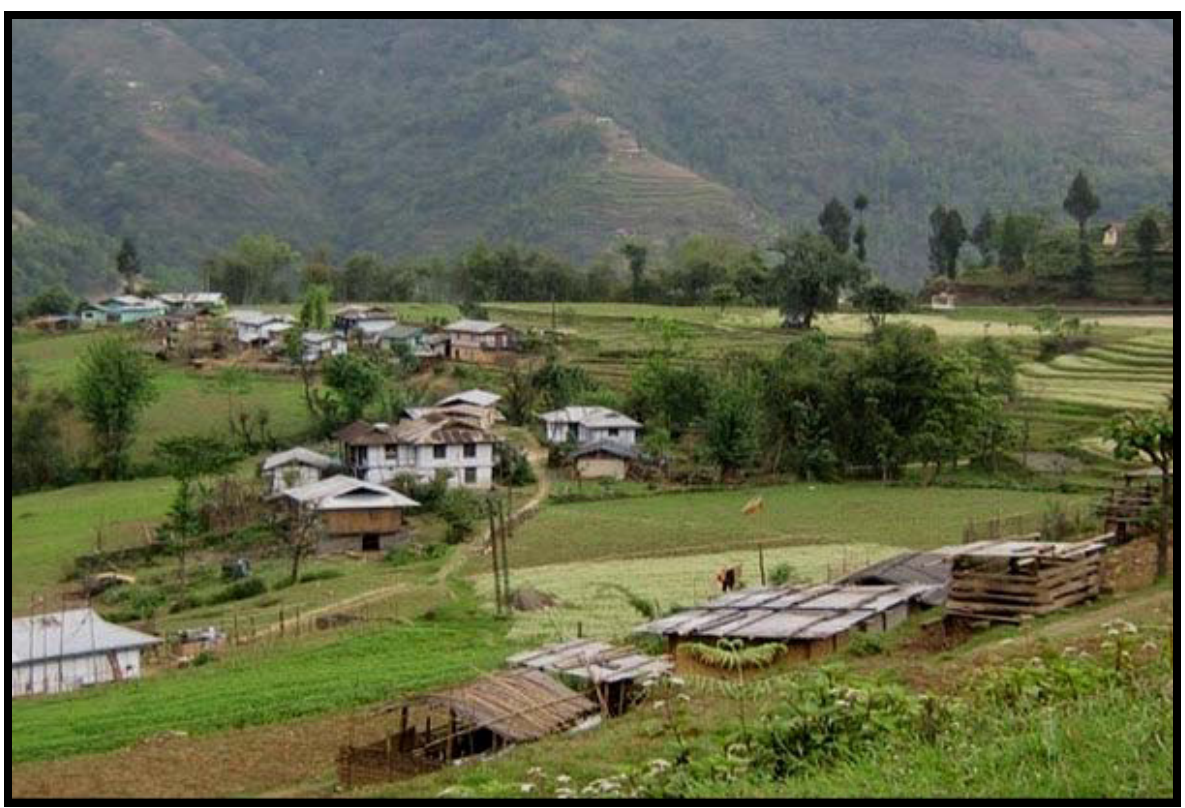

Figure 2. View of Darap village 
The word Darap is originated from the Limboo dialect 'Tan-lop' which literally means a plain or even land. The landscape of the area is moderately steep and gentle unlike other locations in west Sikkim. Darap Village is inhabited mainly by people from the Limboo community and a small number of families from mixed communities like Bhutias, Chettris, Tamangs, Rais, Gurungs and Lepchas. Due to its location Darap possesses great tourism potential in the form of eco-cultural tourism. Culturally and traditionally rich Darap appears photogenic when bough wheat farms bear flowers and harvest takes place. Darap village has exhibited a model for eco-cultural tourism where people from all classes gets involved directly or indirectly in tourism related activities to weed out poverty. In order to attract more number of tourists in the area a number of activities have been introduced. Such activities include traditional way of ploughing the fields, milking cows, cooking by firewood, making and drinking of local brew (chaang, tongba, rakshi), traditional carpet weaving from sheep and yak wool, learning local language, sharing folktales, village and jungle walks, etc which generated a lot of interest among the visitors. For the adventurists, the home stays started options of trekking, picniking, angling, swimming and mountain biking. Besides, Darap's proximity to various tourism spots such as the Kanchendzonga National Park and places of historical and scenic significance are an added advantage. Darap is about 10 min drive from upper Pelling towards famous tourist destinations like Yuksam, Khechuperi Lake, Khanchen-dzonga water fall, Sewaro Rock Garden, Rimbi waterfall and Tashiding Monastery.

The Cherry cottages in Darap were constructed in a manner that they are environment friendly using locally available raw materials. The cottages were designed by village elders having traditional expertise and cater to a homely styled accommodation with modern facilities. The cottages with such a setting provide you a complete solace away from the hub of urban life. Cherry Village Homestay is run by family members with the help of supporting staffs. Comfort to guests is given much importance with priority to cleanliness and hygiene.

\subsection{A day's Experience by a Visitor}

An eco-cultural tourist can start his day with an excursion to the Rimbi river side located at Asallah valley which is a popular picnic spot and well loved and appreciated by adventurers. This spot is known to be a great attraction for those interested in fishing being an anglers' paradise. Lunch with 'Assala', a local fish having a unique taste is delicious giving much satisfaction to the visitors. This fish variety particularly found in this area has encouraged fishing to be a common activity among the locals. Angling during day time and evening barbeque with 'Chaang' a traditional brewery prepared from well matured fermented upland millet sets the right cultural tune to the visitors. The visitors are then entertained by cultural dances and music where traditional costumes and jewelry is displayed much to the visitors' expectation.

Trekkers who would love to take a jungle trek would visit Rani Dhunga - a place of historical and religious fervor. Rani Dhunga commands the sublime view of Mt. Khanchendzonga the 3rd highest summit in the world always treated with respect as a local deity. Lunch served during the day is purely organic much to the visitors' delight and the evening is rewarded by a glass of 'tongba' another local brewery along with a cultural exposition through dance and music by the local youths followed by bon fire.

\subsection{Other Tourists' Activities}

Touristic activities in the form of responsible tourism have been noticed at Darap village where the visitors are being trained in the art of milking the cows in the morning and evening. For many urban settlers this was a lifetime experience in which most of the visitors enjoyed and participated with great enthusiasm. Activities that also stimulate the visitors also include working in the agricultural fields using traditional methods and implements which stirred one's physique and mind especially to the male visitors. On the contrary female visitors normally gets occupied by learning the traditional method of processing butter and cheese a local popular product known as 'chirpi' and also engaging 
in the daily activities of the village people like cooking in the home-stay kitchen such as learning to prepare and cook 'momos', a much preferred local cusine.

Nature walks and bird watching in the forest tracks and nearby streams or hiking to other nearby villages are some of the interests visitors generally undertake during their stay in the village which also includes a visit to a 200 year old Limboo traditional house laid with solid mud floors and adorned by tar-encrusted ceilings through the constantly burning of firewood. This traditional hut normally serves butter and salt tea, millet beer, rakshi-made from rhododendrons or maize, locally known as 'roxy' and creamy milk straight from the cow to the visitors. Darap village is a living testimony of the Limboo culture and tradition that blends with natural resources and biodiversity more than anywhere in the state of Sikkim.

\subsection{Economic Status of Darap village vis-à-vis Eco-Cultural Tourism}

Darap village earlier faced a lot of challenges with regard to livelihood and health status. Poverty was prevalent and the villages were engaged mainly in cattle rearing, raising small poultry units of local variety, resource extraction from primary forests such as edible herbs, timber felling for construction, charcoal and fuel-wood. Forest and shrub burning during the springtime was extensive. Shifting cultivation is largely prevalent with cultivation of upland rice, millets, maize and few vegetables and spices are common and largely subsistent. With the introduction of tourism in Darap, a wide range of employment opportunities is generated with a regular flow of earning thereby improving the livelihood both directly and indirectly. The idea of developing the village, as an offbeat destination for tourists in the form of eco-cultural tourism has changed the lifestyle of the local people. Ninety percent of organic vegetables and meat produced within the village is now consumed by the tourists.

Darap homestays started with a humble beginning since the year 2005 where only 8 (eight) families started this venture in which the initial 3-4 years was meager. However, after a brief period of time, that is, from 2009 onwards there were drastic changes that took place with respect to the growth of this economic activity. The main reason for its growth is through the references that the visitors spread by way of mouth; to friends, relatives, associates etc. This is with respect to the experiences they encountered throughout their stay be it with regard to the alluring scenery, its aesthetic beauty, the quietness and calmness of the village and the great hospitality and friendliness of the villagers. Participation in various activities of the eco-tourists be it at household level or outdoors in the gardens or agricultural fields or adventure through trekking, fishing etc and refreshing village paths and nature walks.

Table 2. Visitation to Cherry Village Homestays at Darap, West Sikkim

\begin{tabular}{|c|c|c|c|c|c|c|c|}
\hline Year & No. of tourists & \multicolumn{2}{|c|}{ Type of tourists } & \multicolumn{2}{c|}{ Av. duration of stay } & \multicolumn{2}{|c|}{$\begin{array}{c}\text { Av. } \\
\text { Spending/day/couple } \\
\text { (Rs) }\end{array}$} \\
\hline & & Domestic & International & Domestic & International & Domestic & $\begin{array}{c}\text { Internati } \\
\text { onal }\end{array}$ \\
\hline 2009 & 1112 & 526 & 592 & 2 & 4 & & \\
\hline 2010 & 1377 & 579 & 798 & 3 & 4 & & \multirow{2}{*}{4000} \\
\hline 2011 & 1800 & 852 & 948 & 4 & 5 & \\
\hline 2012 & 2070 & 974 & 1096 & 4 & 6 & & \\
\hline 2013 & 2200 & 1077 & 1123 & 4 & 6 & & \\
\hline
\end{tabular}


Homestay tariff ranges between Rs.1500/- for a couple to Rs.3000/- per cottage. This covers accommodation with a complimentary vegetarian breakfast (with eggs) and dinner. Different rates are then charged for different activities depending on the choice of the visitor. Through a variety of tourist attractions both ecological and cultural and a host of activities, the homestays have managed to pull more than 5,000 visitors including a few hundred foreigners in the year 2012-13. It is estimated that each household having a homestay fetched an average income of Rs. 1, 15,000 during the tourist season (2012-13). The tourist season starts from the middle of March till the end of May and then October till the middle of November.

Foreign tourists in great numbers are encountered during the winters. With the multiplying effect of the tourism industry other sectors such as the organic farming sector, the weaving sector, apiculture, carpet making from yak and sheep wool, handicrafts, etc. improved tremendously. Many young energetic male youths have engaged themselves as guides, porters and in transport services. Both males and female youths exhibited their talent through folk songs and traditional dances in their traditional attire and costumes.

Local economy greatly improved over the last half a decade with the advent of eco-cultural tourism for eg. Cherry Village home-stay in 2010, with its five rooms managed to garner an income of Rs.18,90, 000 between March to May 2011. It hosted 852 domestic tourists and 948 overseas guests with room tariff ranging between Rs 1500-1800, inclusive of breakfast and one time meal for two persons.

\section{Findings and Discussion}

Northeast India is one of the most mesmerising regions of the Indian sub-continent. Geographically this region supports a diversity of landscapes; from rugged, hilly and mountainous to undulating, flat hill tops and gentle slopes to vast alluvial plains. Enveloped by the Himalayas in the northern portion and the Bangladesh plains in the southern portion the region has a wide altitudinal differentiation that ranges between $50-5500 \mathrm{~m}$ above sea level. With such diversity it supports a large variety of both flora and fauna and is identified as the richest bio-diversity region of the sub-continent. This is reflected in the different humid forest types ranging from tropical forests - sub-tropical forests mixed deciduous forests - temperate forests. On the contrary, amidst such richness the region is facing a serious threat with the depletion of biological resources being one of the 13 major biological hotspots of the world. Many rare and endangered species have been documented especially that of medicinal and aromatic plants though much work is still yet to be done in this respect.

Economically, northeast India is still backward in comparison to the rest of India. As mentioned earlier, the region houses a host of tribes and sub-tribes having their own distinctive culture and tradition. Agriculture and cattle rearing is the main occupation of the rural population of the region. Their agricultural practices are being largely traditional and subsistence in nature. The rural population of northeast India including that of Darap village of West Sikkim practices jhum also known as slash and burn cultivation or shifting cultivation otherwise similar to that of swidden cultivation. Due to this agricultural practice which also have traditional and cultural ties have had an impact on vast span of forestland converted to agricultural fields.

These fields after being cleared and cultivated for one year are left fallow for 3 - 7 years depending upon the jhum cycle. Subsistence crops like upland rice, millets, maize and vegetables are being raised in these agricultural fields. Another important economic activity of the region is cattle rearing. During the dry season (Feb - March) vast forest areas are being burnt where dry undergrowth, shrubs, herbs, etc. are being cleared enabling new grass to sprout for need of cattle feed which is also detrimental to floral diversity especially to ground flora. These two activities have led to a negative impact on the physical environment leading to degradation and depletion of forest resources. In addition timber logging, charcoal burning, extraction of important medicinal and aromatic plants has been detrimental to sustainable growth of the region. 
The initiative of seeking alternatives to livelihood has been a major concern for the region as a whole. As mentioned earlier the region is being blessed by bountiful of natural resources with much variety of culture and tradition. Therefore, one such alternative as discussed throughout the paper is the potential of eco-cultural tourism. This form of activity as investigated shows that there is a perfect blending of the ecological setup with its aesthetic beauty along with culture be it through lifestyle, food habits, language, dress and ornaments, dances and festivals, weaving and handicraft, farming techniques, traditional cuisines, creating much attraction to visitors. Moreover, it contributes also a lot to the local economy of the village.

Homestays are being identified as the most attractive experience by the tourist. Here the tourist(s) stays with the household who extends such accommodation as paying guest and participates along with the family in their day-to-day activities, in accordance to their own wish such as cooking, room cleaning as such other daily chores. The tourists also eat and dine along with the household and the food normally given is basically vegetarian. Non-vegetarian is provided on request by the guests. Other activities of the tourists may include by engaging themselves with the host in the agricultural fields or in weaving and also in making handicraft items that adds to the interest of the visitors making their visit more activity based.

Long treks, nature walks, adventure sports with activities such as fishing, rafting, mountaineering includes as part of their eco-cultural tourism activity depending on the choice of the tourist. The evenings are normally sitting around a bonfire relaxing with traditional drinks and beverages and being entertained through folk songs and dances. Story telling in the form of folk tales and teaching the local language/dialect is also an added feature during the stay. Knowledge of traditional values, taboos, indigenous knowledge etc is often been related during interactions and discussions. Therefore, it is found that blending of both the local environmental setting and culture forms a perfect cultural landscape of value based tourism.

However, this economic activity in the form of eco-cultural tourism not only that it mesmerises the tourist but also contributes to the standard of living of the people. Darap before such activity is riddled with poverty and most of the families live in unhealthy conditions triggering various health problems. With the advent of eco-cultural tourism the village has stepped into sustainable livelihood with the population being benefitted directly or indirectly through this form of tourism as it has its own multiplier effect. The most appealing part is the preparation of meals or food items by organic products. Most of the vegetables and other horticultural products are organic, thereby, the villages to get better rates for their products. As such such form of economic activity has raised the income level of the people of Darap village.

\section{Conclusion}

Darap village one of the eco-cultural tourism destination around Kachandzonga National Park has huge potentiality of attracting tourists. This form of tourism is much healthy than the conventional form as it is highly activity based. It brings about a learning process particularly to the younger generation to understand ones culture and tradition. It conserves both the environment and exhibits culture in the best form through rural lifestyle bringing about sustainability and best known as responsible tourism.

\section{References}

1. J. Hendry, Reclaiming culture: Indigenous people and self-representations, New York: Palgrave MacMillan (2005)

2. G. Richards, Culture tourism: Global and local perspectives (Ed.), New York: Routledge Taylor \& Francis Group (2007)

3. H. Ceballos Lascurian, Tourism, Ecotourism and Protected areas, ICUN, Gland, Switzerland (1996) 
4. L. Mercado and J.P. Lassoie, Assessing Tourists preferences for recreational and environmental Management Programmes Central to the sustainable development of a tourism area in the Domanican Republic, Environment, Development and Sustainability, 4, 253-278 (2002)

5. E. Cater and G. Lowman, Ecotourism a Sustainable Option? John Wiley and Sons, U.K. (1994)

6. G.F. Stiles and D.A. Clark, Conservation of tropical rain forest birds: a case study from Costa Rica.

American Birds 43, 420-428 (1989)

7. S.E. Place, Nature tourism and rural development in Tortuguero. Annals of Tourism Research 18, 186-201(1991)

8. D.V.D.M. Ruschmann Ecological tourism in Brazil. Tourism Management 13, 125-128 (1992)

9. D. Fennell, Ecotourism: An introduction, London: Routledge (1999)

10. Agenda 21 for the Travel \& Tourism Industry: Towards Environmentally Sustainable Development (1996) 